\title{
Design and Fabrication of Steam Sanitiser
}

\author{
Ramachandran N, Ajay aravind J, Ajith Kumar M, Dhivakar M, Dinesh krishna M
}

\begin{abstract}
We use water from taps to wash our hands and subsequently hand blowers to dry them. As we think our hands are clean, still the possibility of germs, bacteria, microbes and mites remain in hands which may have come from the water or the air is used in this cleaning process. The steam sanitizer project is to design and manufacture an equipment to help people sanities their hands instead of washing. In this equipment steam is used instead of water and so the problem of water wastage does not exist..
\end{abstract}

Keywords: water, cleaning process, equipment steam

\section{INTRODUCTION}

Steam sanitiser is a machine which is used to clean their hands by using steam. We mainly done in project to sanitiser the hands and thus it remove dusts. The steam sanitiser project is to design and manufacture n equipment to help people sanitiser their hands instead of washing. In this equipment steam is used instead of water wastage does not exist. A design of steam sanitiser contains various parts such as storage tank, heating coil, sensor, thermostat etc. It can be used in hospitals, bakeries and hotels. It works on the principles of evaporation.

\subsection{Objective}

- The basic aim of our project is to design model that uses steam a main purpose of washing. The project is used to prepare steam that has function of washing

- The design is such that we are trying to make the model as compact as possible also the availability of portability.

- The model is supposed to be very handy and also long life.

- The aim is also uses of destroy bacteria and killing germs.

Revised Manuscript Received on February 05, 2020.

* Correspondence Author

Ramachandran $\mathbf{N}^{*}$, Department of Mechanical Engineering, Sri Krishna College of Engineering and Technology, Coimbatore, India. E-mail: Ramachandrann@skcet.ac.in

Ajay aravind J, Department of Mechanical Engineering, Sri Krishna College of Engineering and Technology, Coimbatore, India. E-mail: 18eumc501@skcet.ac.in

Ajithkumar M, Department of Mechanical Engineering, Sri Krishna College of Engineering and Technology, Coimbatore, India, E-mail: 18eumc502@skcet.ac.in

Dhivakar M, Department of Mechanical Engineering, Sri Krishna College of Engineering and Technology, Coimbatore, India, E-mail: 18eumc507@skcet.ac.in

Dinesh krishna M, Department of Mechanical Engineering, Sri Krishna College of Engineering and Technology, Coimbatore, India, E-mail: 17eumc042@skcet.ac.in

(c) The Authors. Published by Blue Eyes Intelligence Engineering and Sciences Publication (BEIESP). This is an open access article under the CC BY-NC-ND license (http://creativecommons.org/licenses/by-nc-nd/4.0/)

\subsection{Reason for preparing steam}

- With the change in the era, the steam has achieved great importance as human have found great use. Steam is chosen as the best alternative because primarily it is easily available. Well steam can be prepared by simply heating the water and then being used up.

- Although the process of steam cleaning is generally thought to be only for cleaning the carpet, the same processes can be used for cleaning jewelry, bathroom tile and brick. Various types of cleaners are used for the cleaning process by steam depending on the particular application.

- The steam is the medium through which any area that out of reach human hands can be cleaned. With high amount of steam pressure not only the unreachable area would be cleaned but also the microorganisms would get washed off.

- This is also used as the water is mostly available at every location so the steam cleaning makes its application in wide location. So at any individual where we have water system can work.

\section{METHODOLOGY}

\begin{tabular}{|c|}
\hline \multicolumn{2}{|c|}{ Heating coil is fixed with storage tank } \\
\hline Thermostat is inserted into storage tank at $90^{\circ} \mathrm{C}$ \\
\hline PCB control board and sensors are fixed with suitable \\
conditions \\
\hline Relay is connected to the circuit \\
\hline \\
Fan is attached \\
\hline
\end{tabular}

Fig 2.1 Methodology

The fabrication of the steam sanitiser is starts from fixing the heating coils into the storage tank as per the specifications. The water is heating at max temperature. Thermostat is inserted to maintain the temperature level of $90^{\circ} \mathrm{C}$. Printed circuit boards are used in all but the simplest electronic products. They are also used in some electrical products, such as passive switch boxes. A sensor's sensitivity indicates how much the sensor's output changes when the input quantity being measured changes.

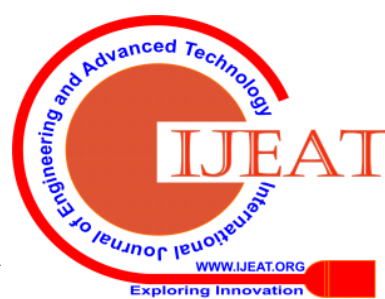


For instance, if the mercury in a thermometer moves $1 \mathrm{~cm}$ when the temperature changes by $1{ }^{\circ} \mathrm{C}$, the sensitivity is $1 \mathrm{~cm} /{ }^{\circ} \mathrm{C}$ (it is basically the slope Dy/Dx assuming a linear characteristic). Sensors are usually designed to have a small effect on what is measured; making the sensor smaller often improves this and may introduce other advantages. A relay is an electromagnetic switch operated by a relatively small electric current that can turn on or off a much larger electric current. The heart of a relay is an electromagnet (a coil f wire that becomes a temporary magnet when electricity flows through it). Attaching an internal fan is a fairly simple way to direct the steam towards the hand.

\section{COMPONENTS OF MACHINE}

The design of steam sanitizer is used to clean their hands by using steam. The steam is generated through the tank.

Our project mainly works on the evaporation. Evaporation is a type of vaporization that occurs on the surface of a liquid (Water) as it changes into the gaseous (Steam) phase. Evaporation is an essential part of the water cycle.

The surrounding gas must not be saturated with the evaporation substance.

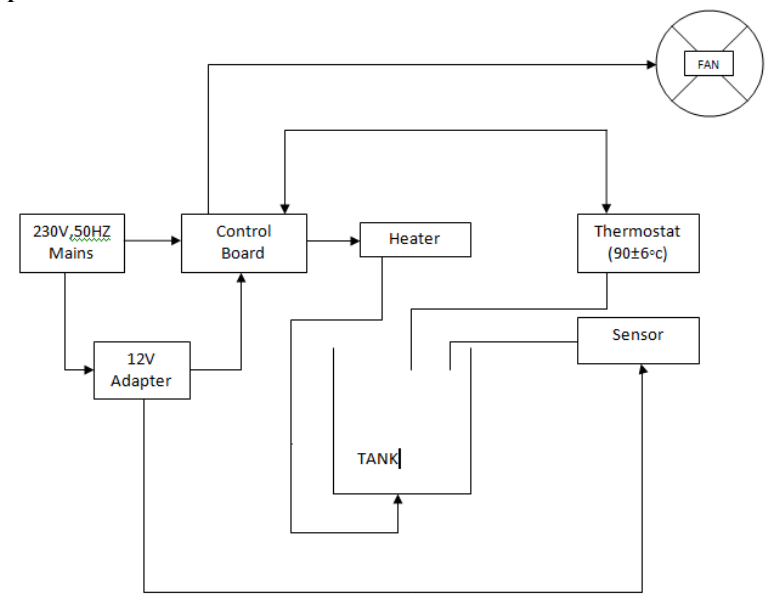

Fig: 3.1 Block Diagram

\subsection{Tank}

A water tank is a container for storing water. Water tank parameters include the general design of the tank, and choice of construction materials, linings. Various materials are used for making a water tank such as plastics, steel, etc...., In our project, we use plastic material.

\section{Specifications:}

The capacity of the tank is 1 liter.

\subsection{Heating coil} or corrugated) or a piece of wire, which is a lamp fiber that increases heat. When an electric current flows through it, it glows red hot and converts the heat into the electrical energy that goes through it, emitting it in all directions. Generally, heat coils are used to heat water for application, here we use sink rods. The heating element within each electric heater is an electrical resistor and operates on the principle of Joule heating: an electric current passing through a resistor converts that electrical energy into heat. The heating element inside the heater in the sinking roe TS is resistant to electricity, and it converts electrical energy into heat, so it is submerged in water and convection takes place in the middle.
Typical heating elements are usually a coil, tape (straight

Metal-resistant heating elements can be wire or tape, straight or curled.

They are used in common heating devices such as toasters and hair dryers, fumes for industrial warming, floor heating, roof heating, ice melting path heating, dryers.

The heating elements are generally nickel-based, usually an alloy (a mixture of metals and sometimes chemical elements) (80\% nickel and 20\% chromium) (other compounds of nichrome are available, but the 80-20 alloy is more common). They are good reasons why nichrome is the most popular ingredient for heating the elements: it has a high melting point (about $1400^{\circ} \mathrm{C}$ or $2550^{\circ} \mathrm{F}$ ), does not oxidize (even at high temperatures), does not expand too much, warms up, and has a fair (not too high, reasonably stable) resistance. (This is the maximum temperature for room temperature only about 10 percent of the temperature increases between Lie).

\section{Specifications}

Voltage - 220-240V

Power - 36W

\subsection{Sensor}

Detect body heat (infrared energy). Passive infrared sensors are the most widely used movements in home marine systems. When activated. Once the sensor is off, it detects heat and movement in the surrounding area, forming a protective "grid." Your system is AMAT, your movements are sensors

Sensors are used in everyday objects, touch-sensitive boost buttons (tactile sensors) and lights 919 make any site dim or bright, touching any site most people will never know. With advances in micro machines and easy to use microcontroller platforms. The applications of sensors have expanded beyond traditional fields of temperature, pressure or flow measurement into MARG sensors. Furthermore, analog sensors, potentiometers, and force-sensing resistors are still widely used. Applications include manufacturing and engines, aircraft and aerospace, cars, medicine, robotics and many other aspects of our daily lives. In this, we use the proximity type sensor.

A sensor's sensitivity refers to how much the sensor's output changes when the input level is measured. For example, if mercury moves at 1 a.m. morning when the temperature turns to $1^{\circ} \mathrm{C}$, the sensitivity is $1 \mathrm{~cm} /{ }^{\circ} \mathrm{C}$ (which is a linear characteristic (Dy / Dx)). Some sensors can also affect how they are measured; For example, a room temperature thermometer. Sensors are generally designed to have a small effect $n$ is measured; Replacing the sensor often improves this and technological advancement allows the development of more and more sensors at the microscope using MEMS technology. In most cases, the micro-sensor achieves significantly higher speed and sensitivity compared to macroscopic approaches. Other advantages of Introductory toys.

\subsection{Thermostat}

A thermostat is the temperature of the system so that the temperature of the system is maintained close to the desired set point.

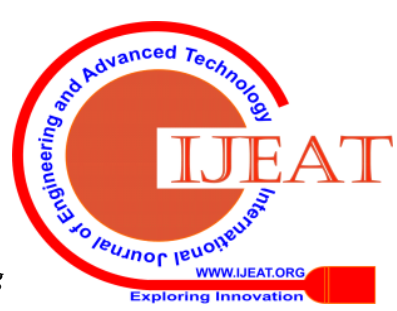


A set-point temperature of the heating or cooling system from any device or used illustrations, building heating, central heating, air conditioners, water heaters, ovens and refrigerator, and medical and scientific archives content gia includes kitchen equipment.

Thermostatically controlled loads comprise roughly 50\% of the overall electricity demand in the united states.

\section{Specifications}

Current - 20A

Temperature - $100 \pm 6^{\circ} \mathrm{C}$

\subsection{Fan}

Fan cooled motors have many common uses in motors that either produce an alt of heat or have poor airflow because they are always stationary or in an enclosed space and require a compact cooling system. They are common for industrial users, household appliances such as blenders and mixers, power tools such as drills and rotary tools, and radio-controlled cars attaching an internal fan to a motor is a fairly simple way to cool it. Internal fan cling also takes up far less space than external fan cooling or water cooling.

\subsection{Relay}

The control circuit function as the coupling between the input and output circuits. In electromechanical relays, the coil accomplishes this function. A relays Output Circuit is the portion of the relay that switches on the load and performs the same function as the mechanical contacts of electromechanical relays.

A relay is an electromagnetic switch operated by a relatively small electric current that can turn on or off a much larger electric current. Electromagnet (a wire that becomes a temporary magnet when a coil of electricity flows through it).

\section{WORKING PRINCIPAL}

Usually, when people want to wash their hands, they should wash their hands with water. Steam purification program is the design and handling of equipment to help people clean their hands instead of washing their hands.

The operational principle of the project is to use a steam generator, where the water is heated in a coil, which is kept at temperature. The thermostat is fixed in a tank and it is set to a constant temperature $\left(90+6{ }^{\circ} \mathrm{C}\right)$. When a person holds their hand to clean the sensor, their hands and the healing supply $\mathrm{d}$ thermostat is turned into steam.

Now the steam is injected into the person's hands so that he can get his hand sanitizer. The vapor and thermal efficiency of the steam can be adjusted by controlling the flow of water through the sensor and the temperature of the thermostat.

\section{MERITS}

- Killing germs, bacteria and micro-organisms such as dust mites.

- It can be used in bakeries, hotels, hospitals, kitchens, etc.....,

- By using this we can save the water.

- By using sanitiser we can avoid the pollution.

- Easy and simple in construction.

- Maintenance cost is not necessary.

- Easily replaceable

\section{RESULT ANALYSIS}

\subsection{Calculation}

Power:

$$
\begin{gathered}
\mathrm{P}=2 \pi \mathrm{NT} / 60 \\
\mathrm{~T}=\mathrm{F}^{*} \mathrm{r}=10.49 * 0.25=2.62 \mathrm{~N}-\mathrm{m} \\
\mathrm{P}=2 \pi * 250 * 2.62 / 60 \\
=69+36+90 \\
\mathrm{P}=195 \text { Watts }
\end{gathered}
$$

Heat discharge:

$$
\begin{gathered}
\mathrm{Q}=\mathrm{a}_{1} \mathrm{v}_{1}=\mathrm{a}_{2} \mathrm{~V}_{2} \\
\mathrm{~A}_{1}=\pi / 4 *\left(\mathrm{~d}^{2}\right)=\pi / 4 *\left(15^{2}\right)=176.62 \mathrm{~mm}^{2} \\
\mathrm{~A}_{2}=\pi / 4 *\left(\mathrm{~d}^{2}\right)=\pi / 4 *\left(20^{2}\right)=314.15 \mathrm{~mm}^{2} \\
\mathrm{a}_{1} \mathrm{~V}_{1}=\mathrm{a}_{2} \mathrm{~V}_{2} \\
\mathrm{v}_{1}=\mathrm{a}_{2} \mathrm{~V}_{2} / \mathrm{a}_{1}=176.62 * \mathrm{v}_{2} / 314.15 \\
\mathrm{v}_{1}=1.8 \mathrm{v}_{2}
\end{gathered}
$$

Bernoulli's Equation:

$$
\begin{aligned}
& \left(\mathrm{P}_{1}-\mathrm{P}_{2}\right) / \rho g+\left(\mathrm{V}_{2}-\mathrm{V}_{1}\right) / 2 \mathrm{~g}+\mathrm{Z}=\mathrm{C} \\
& (4-1.6) * 10^{6} / 1000 * 9.81+\left(\mathrm{v}_{2}-1.8 \mathrm{v}_{2}\right) / 2 * 9.81+0.1=
\end{aligned}
$$

4.18

$$
\begin{aligned}
\mathrm{v}_{2} & =5900.77 \mathrm{~m} / \mathrm{s} \\
\mathrm{v}_{1} & =1.8 \mathrm{v}_{2}=1.8 * 5900.77 \\
\mathrm{v}_{1} & =10621.38 \mathrm{~m} / \mathrm{s} \\
\mathrm{Q} & =\mathrm{a}_{1} \mathrm{~V}_{1} \\
& =\left(176.6 * 10^{-6}\right) *(10621.38) \\
\mathrm{Q} & =1.87 \mathrm{~m}^{3} / \mathrm{sec}
\end{aligned}
$$

Heat produced:

$$
\begin{aligned}
\mathrm{H} & =\mathrm{I}^{2} \mathrm{Rt}=\mathrm{Pt} \\
& =36^{*} 60=2160 \mathrm{~J}
\end{aligned}
$$

$$
\mathrm{P}=\mathrm{VI}=\mathrm{I}^{2} \mathrm{R}
$$$$
\mathrm{H}=\mathrm{Pt}
$$

\subsection{Comparison with available model}

\begin{tabular}{|l|c|c|}
\hline & Available model & Our model \\
\hline Total power & 3000 watts & 195 watts \\
\hline $\begin{array}{l}\text { Water } \\
\text { consumption }\end{array}$ & $850 \mathrm{ml}$ & $400 \mathrm{ml}$ \\
\hline Weight & $10 \mathrm{~kg}$ & $4 \mathrm{~kg}$ \\
\hline Start up time & $3 \mathrm{~min}$ & $1 \mathrm{~min}$ \\
\hline Cost estimation & 18000 & 8000 \\
\hline Tank capacity & 5liters & $600 \mathrm{ml}$ \\
\hline
\end{tabular}

Since the capacity of the tank is less it is easy to fit anywhere.

\section{CONCLUSION}

Thus, the report has been framed on the details regarding project work: Design of steam sanitizer. We successfully understood in designing a project with the help of academic knowledge and working principle. We learned to decide the components required for executing the design and also learned the process of manufacturing of those parts.

We learn to complete the project in time by suitably deciding the components to be made and components to be bought outside. 


\section{Design and Fabrication of Steam Sanitiser}

\section{REFERENCES}

1. William A. Rutala, Ph.D., M.P.H. Hospital Epidemiology, University of North Carolina Health Care System, Chapel Hill, $\quad$ NC 27514 Division of Infectious Diseases, University of North Carolina School of Medicine, Chapel Hill, NC 27599-7030

2. David J. Weber, M.D.,

M.P.H. Hospital Epidemiology, University of North Carolina Health Care System, Chapel Hill, $\quad$ NC 27514 Division of Infectious Diseases, University of North Carolina School of Medicine, Chapel Hill, NC 27599-7030

3. Healthcare Infection Control Practices Advisory Committee (HICPAC)

4. Dahlberg, A. C, and Marquardt, J. C. Sterilization of Ice Cream Freezers. New York State Agr. Expt. Sta. Bul. 628. April 1933.

5. Amer. Pub. Health Assoc. Standard Methods for the Examination of Dairy Products. 7th Edition, 1939. New York.

6. Amer. Pub. Health Assoc. Standard Methods for the Examination of Dairy Products. 8th Edition, Am. P. H. Assn. New York.(Unpublished).

7. Standard Technie Proposed by Sub-Committee onStandard Methods for the Examination of Dishwashing Devices of the Committee on Research and Standards. A. P. Hitchens, Chairman. 7th Annual Yr. Book 1936 -37 pp. 45-58.

\section{AUTHORS PROFILE}

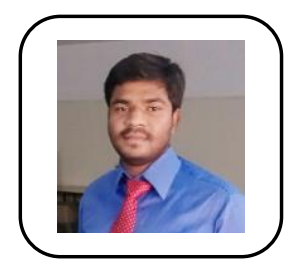

N.Ramachandran, Assistant Professor, Department of Mechanical Engineering, Sri Krishna College of Engineering and Technology,Coimbatore. I have completed my Under Graduation at Shri Angalamman College of Engineering and Technology, Trichy. And also, I have completed my Post Graduation at Bannari Amman College of Engineering, Sathyamangalam. I have Published 17 paper in reputed international journals. And, I would like to highlight that, I have received a fund of Rs.25,00,000 from SYINDA INVENTORS PRIVATE LIMITED for the project titled F-BOT.And also I have received a fund of Rs.7,500 from TNSCST(Tamilnadu State Council for Science and Technology) for the project titled "Design and Fabrication of Stair Climbing Load Carrier". Being a Principal Investigator me and my team submitted 2 proposals for DST (Department of Science and Technology) entitled "Design and fabrication of fire fighting robot with smart camera" under SYST(Scheme for Young Scientists and Technologists) scheme and "Development of IOT based CNC Farming Machine" ,under DST (SUSTAINABLE \& INNOVATIVE TECHNOLOGIES IN AGRICULTURE (AGRO-TECH) as well as under the scheme of TDP (Technology Development Programme).Recently we have submitted a project proposal for LA Foundation under Dessault Systems with the project titled "Design and fabrication of fire fighting robot with smart camera". I have published 5 patents. I have also been awarded as the Best Faculty in Mechanical Engineering Department for the year 2018-2019 by Sri Krishna College of Engineering and Technology, Coimbatore.

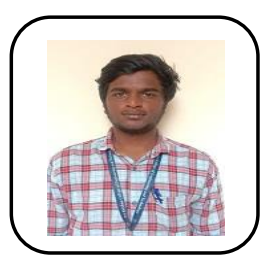

Ajay Aravind $\mathbf{J}$, Under Graduate student, Department of Mechanical Engineering, Sri Krishna College of Engineering and Technology, Coimbatore. I have success fully completed NPTEL course in Ethics and engineering practice. I have a done mini project (Design and fabrication of pneumatic coconut husk remover). Won $1^{\text {st }}$ place in mini project (Automatic bike crush detection system). I have successfully completed industrial training 28 days in bajaj.

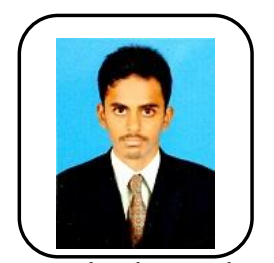

Ajithkumar M, Under Graduate student, Department of Mechanical Engineering, Sri Krishna College of Engineering and Technology, Coimbatore. I have success fully completed NPTEL course in Ethics and engineering practice. I have won 3rd place in the event of paper presentation in the National Level Technical Symposium, successfully completed my gokart event, I have done mini project of automatic bomb detector system, I have successfully completed industrial training 21 days in Maruthi Suzuki.

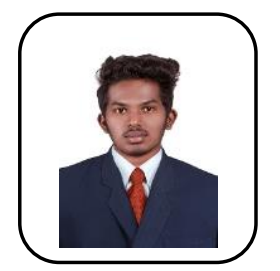

Dhivakar M, Under Graduate student, Department of Mechanical Engineering, Sri Krishna College of Engineering and Technology, Coimbatore. I have success fully completed NPTEL course in Speaking Effectively. I have won 2nd place in the event of paper presentation in the National Level Technical Symposium.successfully done many projects likes Design and Fabrication of Swing motion power generator, Design and Fabrication of Solar Air Dryer. I have success fully completed Industrial Training 21 days in Eltex super castings.

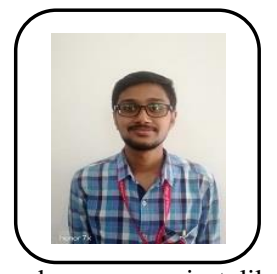

Dinesh Krishna M, Under Graduate student, Department of Mechanical Engineering, Sri Krishna College of Engineering and Technology, Coimbatore. I have success fully completed NPTEL course in Ethics and engineering practice. I have done design and fabrication of gokart steering system. I have completed one day technical workshop in karivardhan motors. I have successfully done my project like bomb detecting robot and design and fabrication gearless mechanism. 